\title{
Poetic and Prosaic Metaphors
}

\author{
Geoffrey Nunberg \\ Xerox PARC and CSLI, Stanford
}

Metaphor (some people say) is "the dreamwork of language," where ideas are combined in ways that are "special, odd, or startling." Metaphor is a "mutation" of language, a phenomenon that relies crucially on our recognition of its "deviance" or "nonsensicality." Metaphor, if it means at all (it may only "suggest" or "evoke"), does not mean as literal language does. Metaphor is the stuff of "playful prose and high poetic art."

Metaphor (say others) "covers the entire semantic, semiological and performative field of language" and "is natural and widespread in our speech, not having any apparent special status."

Well, but (we say) there are ways and ways of being a metaphor. What some people are talking about are the "fresh" and "vivid" figures that pullulate in poetry, play, and the rudimentary stages of theory-building. For them, metaphor is essentially an rhetorical category, identified by its affective import. Whereas other people take metaphor to be essentially a semantic phenomenon, which crucially involves a perception of transfer of extension of meaning or application.

In the standard story, moreover, there is no real conflict between these views. Metaphors begin their lives as novel poetic creations with marked rhetorical effects, whose comprehension requires a special imaginative leap. As time goes by, they become a part of general usage, now "stale," "worn," and "idiomatic"; their comprehension becomes more automatic, and their rhetorical effect is dulled. Finally, as "dead" or "frozen" metaphors, they are not psychologically distinct from literally-used terms. In point of fact, "most lexical items prove to be dead metaphors that were alive and kicking at some time in the past." The natural conclusion is that there is a difference in conversational status between the "poetic metaphors" that strike our fancy and the "prosaic metaphors" that pass by unnoticed in our ordinary discourse. The former arise out of conversational implicatures, indirect speech acts, or whatever, while the latter are matters of literal or conventional meaning. Not surprisingly, this leads in turn to the assumption that we ought to be able to explain the rhetorical effect of poetic metaphors in virtue of their conversational properties, as something that grows directly out of the process of inference required in non-literal comprehension.

The standard story does explain some of the differences in our intuitive reactions we have to metaphorical utterances. It is beyond dispute that metaphors do work their way into literality, and may lose some of their luster along the way. If you say in English "he answered in the wink of an eye" you occasion no special rhetorical effect; but if you say in French "Il a repondu en un clin d'oeil," you may get credit for a slightly clever turn of phrase, simply because the French have not made this expression a commonplace.

But there is more to the distinction between "poetic" and "prosaic" figures than that; ultimately, it transcends dimensions of relative novelty and conventionality. On the one hand, there are extensions of meaning that are so natural, so obvious, that they must surely be have been counted prosaic on first utterance-indeed, they must have been born along with the literal meaning of a term. For example, I imagine that the discovery that the word chicken could be used to refer to chicken meat could not have taken too long once it had been established that the bird was edible. Nor did it want a vast leap of imagination to realize that the word sun could be used to refer to the volume directly illuminated by the sun (as in "we were standing in the sun") or (to take an example from Sam Levin) that the 
word tremble, once applied to the shaking or quivering of an animal, would do as well to describe the oscillations of the earth or of leaves in the wind. In many cases like these, in fact, we may be reluctant to speak of "figures of speech" at all, and say rather that the words chicken, sun and tremble are "polysemous," and have several "related literal meanings." Now if by this we mean only that the extended usages are prosaic and common, and that hearers probably do not work them out afresh on every hearing, then I have no objection to calling these "literal meanings." But it is a mistake to try to argue from our intuition for the unremarkableness of these usages to the conclusion that they are prescribed by language-specific rules or convention, or that the figuration that underlies them is in any sense "dead" or "idiomatic." The uses are unremarkable precisely because they are obvious, and so can take hold in the general practice without the introduction of any special rules. (If you are just learning Italian, say, and know that il sole is the word for the sun, it wouldn't occur to you to check before using the same word to refer to an volume illuminated by the sun. You'd figure-rightly - that the Italians would make the same obvious moves that we do.) In any event, it is clear that the figuration involved in these cases has never had and could never have had the power to startle us.

Much the same point can be made about other transfers of application, which are licensed only by the circumstances of a particular narrow context, and so could not become part of conventional usage. Say you want someone who knows nothing about cars to hand you one of those little tools you use to pry open a spark-plug gap, which in this case happens to be shaped like a clothespin. "Hand me the clothespin," you say metaphorically. Now it's unlikely that your interlocutor has ever heard clochespin used in this way, nor could that word ever become the standard means of referring to spark-plug gap adjusters (which come in different shapes). But your remark is clearly lacking in the divine emollient of poetry.

On the other hand, there is plenty of poetry in many of the metaphors that have been adopted by the general use, even those that have become in some measure conventionalized. Indeed, it is precisely because they are evocative that we have made idioms of expressions like knock one's socks off, lick one's wounds, or steal someone's thunder. It is true that there is a difference between the effect of these figures and those offered in "real poetry" (which by our lights must own an individual author). But there is no missing the spirit of play in these figures, which is absent in the use of clothespin to identify a nameless tool, or of chicken to refer to a kind of meat. This pleasure survives even after the motive for an idiomatic metaphor has been largely obscured. Who knows why we rob Peter to pay Paul, rather than Max to pay Marvin? What is clear is that the personification of exigent circumstances gives them a satisfyingly lighthearted cast, and so in some measure alleviates them.

What I'm calling "poetic" metaphors are just those that we associate with "play," "affect," "evocation," "pleasure," or whatever. (It is not important that we be able to say what pleasure is, so long as we know it when we feel it.) What I'm calling "prosaic metaphors," on the other hand, are those that strike us as involving no-nonsense referential business-as-usual.

Where does the difference between the two types of figures come from? Not, we have seen, from differences in the degree of their conventionality, Nor, surely, from the nature of the mechanism involved transfer or reapplication of the meaning of an expression. The same principles of transfer (based on physical resemblance) that license the prosaic application of clolhespin to a tool result in a poetic (if not exactly sublime) figure when the word is applied to a skinny person. It is not poetic to use beer to refer to the interval of time 
over which beers are served, as in I could have told you the answer two beers ago; it is poetic to use grief in the same way, as in Dylan Thomas's a grief ago.

What makes all the difference here, rather, is the degree to which a usage is justified in terms of a strictly instrumental rationality. I take it as obvious that metaphor and figuration are ways of doing whatever we do with expressions: referring, predicating, and so forth. That is, figuration is a certain way of identifying objects, properties, and relations. For the present purposes, I'll stick to the referring uses of expressions-the clothespin, that witch, and so on. Let's say that a figurative use of such a expression is instrumentally rational in a given context if a rational agent would conclude that this use offers the speaker an optimal probability of success in enabling the hearer to identify the thing he is talking about, for such purposes as are conversationally relevant, and that it is that consideration that motivated the speaker to use the expression in that way. (This definition would require various qualifications before it could be airtight, but it will do for here.)

Take the case in which we want to enable someone to pick out a tool from among an array. In this case, the tool has no commonly used name, and even if it did, we could not expect that an automotively unsophisticated hearer would be able to identify this tool solely on the basis of its appearance, armed only with its name. A description of its function ("the gap adjuster") would be of no more use, for the same reasons. We are left with getting the hearer to identify it in virtue of its appearance, either by describing it in such terms ("the little thing with two prongs"), or by describing it using the name of something else-a clothespin, a fork, whatever-that it resembles more than anything else in the array. Now there are any number of factors that might make one or the other of these approaches the optimal strategy for accomplishing reference. It depends how easily the protrusions on the tool are identified as prongs, how much the tool looks in silhouette like a typical clothespin, how likely it is in this context that the speaker might have been looking for an actual clothespin, or that the hearer might have thought he could have been looking for an actual clothespin, and so on. Then too, you have to calculate the likelihood-here, pretty goodthat the hearer will know that the speaker will be going after the referent in virtue of its appearance, rather than its function or something else. And of course you have to run all these factors through various strategies for arriving at common belief. But it is clear enough that the speaker thought it was an optimal way of accomplishing reference, and that that's why he used the term. At the very least, it would be irrational to ascribe to him any ulterior motive.

Now suppose you're trying to get me to try on a jacket with wide horizontal stripes, and I, ample, say "Not me. Offer it to the clothespin you were just talking to." A poetic figure, in our (extremely generous) sense of the term. And it counts as poetic for two reasons. First, it's pretty likely that I could have used another expression-say the skinny fellow, though depending on the circumstances it might do as well to say the man with the red cap, or Jackson-if I were interested only in optimizing the probability that you could pick out the person I had in mind as a reasonable customer for the jacket. This, on the assumption that it's easier to pick out skinny than to pick out clothespin-resembling, at least so far as any array of potential jacket customers is concerned. What's more, you can construct an ulterior motive for my saying things the way l did. Briefly, I'm behaving in a way that would be instrumentally rational if the world were different: in particular, if people like Jackson were most readily picked out in virtue of their physical resemblance to clothespins. (Though in another context, to be sure, I could have been counting on the function of clothespins to enable reference to go through.) This would be the case only if Jackson looked a great deal more like a clothespin than he did like anything else; indeed, if 
he were more readily identifiable as looking like a clothespin than as merely "skinny." Now it could be, I suppose, that I am pretending that clothespins are more anthropomorphic than they are (and there are metaphors that work this way). But it's a sad fact that we take more pleasure in exaggerating the physical peculiarities of people than of household implements; it is funnier to imagine Jackson as looking like nothing so much as a clothespin than to imagine a clothespin looking like nothing so much as Jackson.

Now for the use of beer and grief to refer to intervals. Beers do come at publicly observable intervals, which are moreover the most relevant stages for chopping up the progress of certain evenings. So it is instrumentally rational to use beer to refer to these intervals. Whereas the analogous use of grief would be instrumentally rational only in a world in which the state was generally accepted as recurring with predictable regularity (and probably, in a publicly observable way). To comprehend the usage, then, we have to imagine a world in which our inner states were driven by natural cycles quite as the seasons are. The reason that poetic metaphors are such an important part of the poet's arsenal is not because they say what is false. If they are in fact false-saying (and I would argue they are not), they share this property with prosaic metaphors that have no particular rhetorical effect. Rather, they force us to presuppose what is false. That is what Shelley had in mind, I calculate, when he said (though the italics are mine) that poets are the "unacknowledged legislators of the world."

It is this aspect of play-acting that gives poetic metaphors their affective import, and makes them quite literally playful or dramatic, as the case may be. In this way, poetic metaphors have a great deal in common with ironic utterances and other tropes that involve a pretence (rather than an assertion) that the world is other than it is. Note that it is immaterial whether we actually work out these inferences on each occasion of hearing a familiar or idiomatic poetic metaphor, so long as we recognize that the usage is in fact motivated by such inferences.

If this much is granted, then most of the stories we tell about the aesthetics of metaphor are wrong, or at best misleading. Their impact, when they have one, does not come from their "literal falsity," from their "semantic deviance," from their "indirection," or from the "compression of two ideas into one." Criteria like these do not distinguish poetic from prosaic metaphors. More generally, there is nothing about metaphor qua metaphor (or of conveyed meaning of any sort qua conveyed meaning) that makes it an interesting subject for aesthetic investigation. More generally still, it is a mistake to suppose that we can derive rhetorical categories from purely conversational principles. 